\title{
Experiences of Level 100 Undergraduate Students in Developing Countries: A Case Study in University of Cape Coast, Ghana.
}

\author{
Kwao Edjah ${ }^{1} \&$ Ebenezer Domey $^{2} \&$ Francis Ankomah $^{3}$
}

\author{
${ }^{1 \& 3}$ Department of Educational Foundations, University of Cape Coast, Ghana \\ ${ }^{2}$ Office of the Dean of Students' Affairs, University of Cape Coast, Ghana \\ Correspondence: Francis Ankomah, University of Cape Coast, Ghana. \\ Email: francis.ankomah@stu.ucc.edu.gh
}

Received: April 8, 2019

Accepted: May 25, 2019

Online Published: June 1, 2019

doi: 10.23918/ijsses.v5i4p13

\begin{abstract}
Life at university for the first year can be exciting and challenging. University life becomes exciting when students are able to deal effectively and adapt with their newly found environment. Conversely, life at university becomes catastrophizing when students are not able to successfully go through the adaptation process. Employing the descriptive survey design, 400 first year undergraduate students were selected using the stratified and convenient sampling methods. The study aimed at identifying the transitional challenges students face in their first year of university education, and also determining differences in the transitional challenges students face in their first year of university education with respect to demographic characteristics (gender, age, previous level of education before entry to university, place of dwelling). A questionnaire with a Cronbach's alpha reliability coefficient of .64 was used to gather information from the students. Independent samples t-test, one-way ANOVA were used to analyse the data. It was found that among the challenges that first year university students go through, movement on campus, separation from family, registration of courses, switching between lecture theatres, adjusting to lecture method of teaching, making new friends, and coping with roommates were the prominent ones. It was also found that female students experience more challenges compared with their male counterparts, students from self-contained houses experienced more challenges than those from compound houses. It was further found that experiences of first year students did not vary with respect age. The study concluded that first year students generally are faced with academic and social-related challenges during their first year in the university. It was also concluded that gender, place of dwelling, and previous level of education have influence on students' experiences during their first year in the university, age however have no influence. Academic staff of the students' affairs and counsellors in the university are encouraged to intensify academic and social support for first year students.
\end{abstract}

Keywords: Transition, Tertiary, Challenges, SSS/SHS

\section{Introduction}

Globally, the quest for higher education is on the increase (Mudhovozi, 2012). Entry into university affords students the chance to define and advance their career. Even though students make merry when gain admission to university, it however brings profound uneasiness since some students are breaking from familiar places and people for the first time in their lives (Bernie, Larose, \& Whippie, 2005). AzilaGbettor, Atatsi, Danku, and Soglo (2015) contend that the transition from the high school to university brings about shake to social security, physical comfort, and ability to enjoy satisfying activities for first year students. A university is a new environment that activates different reactions among first year students. Thus, life at university for the first year can be exciting and challenging (Habibah et al., 2010). 
On the one hand, exposure to personal freedom can make a student feel wonderful and worrisome. In addition, parental control ceases and the student is confronted with the new found freedom (Tao, Dong, Pratt, Hunsberger, \& Pancer, 2000). On the other hand, it is incumbent on the student to restructure his or her personal relations in a new environment and this often causes mental and physical distress.

First year period is considered as the bedrock for the whole academic career. It is, therefore, required that transition to university becomes as easy and smooth as possible in order to ensure academic success of students throughout the entire university experience (Tao et al., 2000). Perry and Allard (2003) defined transition as the "internal process in the mind which takes place when students undergo change and pass from the familiar to the unknown, responding to cultural, social and cognitive challenges" (p. 75). Change is something that is inevitable and happens to people; they may or may not agree with it. Whereas change can happen quickly, making an effective transition, it can often take longer.

Some researchers have also examined a variety of these transition difficulties to include: social integration (Berger, 1997; Braxton, Vesper \& Hossley, 1995), academic integration (Allen \& Nelson, 1989), interpersonal relationships (Keup \& Stolzenberg, 2004), homesickness (Fisher \& Hood, 1987), academic stress (Birnie-Lefeovitch, 2000), academic preparation and self-efficacy (Allen \& Nelson, 1989; Berger, 1997), and institutional commitment (Berger \& Milem, 1999). McInnis (2001) argued that a number of academic failure and attrition usually occurs in the first-year at the university, and that students' adjustment into the university has both short-term and long-term implications on students' performance, continuation and overall success in the university. Tao et al. (2000) assert that when transitions are not well-managed, students may undergo some challenges - academic, social, emotional or behavioural problems. Hence, it becomes incumbent on educators to be aware of the particular types of challenges confronting students when they move into university.

Some studies have found gender differences in the students' adjustment; the studies found male students to possess better adjustment levels than female students (Enochs \& Ronald, 2006; Abdallah et al., 2009). Age has also been found as an important factor for successful adjustment of students (Grebennikov \& Skaines, 2009). Grebennikov and Skaines maintain that there are differences between students adjustment based on their age; elder students adjust less as compared to younger students.

Upcraft and Farmsworth (1984) viewed orientation as an effort by an institution to help its students make a successful adjustment. A study in Ghana by Owusu, Tawiah, Sena-Kpeglo and Onyame (2014) on the impact of orientation on performance of undergraduate students in University of Cape Coast revealed a significant impact of orientation on the academic performance of students. Students who participated in orientation programme performed better academically than their counterparts who did not participate in orientation. This shows that students who are not able to adjust well during the first year transitional period in the university encounter academic problems.

Amponsah and Owolabi (2011) postulate that environmental changes, life challenges and periods of transition are common factors that pose stress to college students. Challenging classes, difficult tests and other academic obstacles, including the more independent nature of the college learning structure, finding a room and living with a roommate, balancing friends with school work and dealing with the dynamics of young adult relationships are challenges that lead to stress. Amponsah and Owolabi, in their study on stress levels of fresh university of students using fresh undergraduate students of University of 
Cape Coast found that most of the respondents were stressed. Approximately, $70.4 \%$ were moderately stressed, and $3.5 \%$ were highly stressed.

From the studies reviewed, it is apparent that students go through challenges during transitional periods from senior high schools to tertiary institutions. These challenges pose threat to the academic work of students and their social life. It appears enough research has not been done in Ghana, and specifically in Cape Coast on the transitional challenges students face in tertiary institutions. It is this gap that has necessitated the conduct of this study. This study aimed at identifying the transitional challenges students face in their first year of university education, and also determining differences in the transitional challenges students face in their first year of university education with respect to demographic characteristics (gender, age, previous level of education before entry to university, type of dwelling). Even though the study used University of Cape Coast as a case, this study is relevant to universities in other developing countries, since most universities in these countries have similar administrative structures and challenges.

Hypotheses

$\mathrm{H}_{1}$ 1: There is a statistically significant gender differences in the level of transitional challenges students face in their first year of university education.

$\mathrm{H}_{1}$ 2: There is a statistically significant age differences in the level of transitional challenges students face in their first year of university education.

$\mathrm{H}_{1}$ 3: There is a statistically significant differences in the level of transitional challenges students face in their first year of university education with regards to students from SHS and those from tertiary institutions.

$\mathrm{H}_{1}$ 4: There is a statistically significant differences in the level of transitional challenges students face in their first year of university education with regards to the type of duelling.

\section{Methodology}

The descriptive cross-sectional survey design was employed to conduct this study. This research design was appropriate for this study because, this study aimed at describing the challenges students face in their first year, and how the challenges differ with regards to demographic characteristics. Also, information was collected from students of different age groups at a particular point in time. The population for the study comprised all regular undergraduate first year students of University of Cape Coast (UCC) during the 2016/2017 academic year. The total population according to the Students Records Management and Information System of UCC (SRMIS, 2017), there are 4384 regular undergraduate first year students. A sample of 357 was deemed appropriate for this study (Krejcie \& Morgan, 1970). However, a sample of 400 was chosen for the study. This figure was arrived at having in mind the following factors: the prevalence rate, response rate, and the design effect. The multistage sampling technique was used employed to select the sample for the study. First, the stratified proportionate sampling was used to divide the sample into four strata using the colleges, namely, College of Agriculture and Natural Sciences, College of Education Studies, College of Health and Allied Sciences, and College of Humanities and Legal Studies. The convenient sampling method was finally 
used to select respondents from the respective strata. The convenient sampling method was used because the nature of the dispersion of the population did not mandate the use of simple random sampling.

Questionnaire was used as the data collection instrument. The questionnaire was made up 14 items on a 5-point Likert scale (agreement type scale). The reliability of the transitional challenges scale was estimated using Cronbach's alpha reliability coefficient. The scale had reliability coefficient of .64. Data collection took place during the fourth week of arrival of the first year students. The data was analysed using both descriptive and inferential statistics. The descriptive statistics used were frequencies, percentages, means and standard deviations. Hypotheses 1, 3, and 4 were tested using independent samples t-test. This statistical procedure was used because these hypotheses sought to compare the experiences of students in two categories (gender, previous, and type of dwelling). Above all, the data met the normality, homogeneity of variance and independent of observations assumptions. One-way analysis of variance (ANOVA) was used to test for Hypothesis 2. This procedure was used because the hypothesis sought to find differences in experiences of first year students in terms of age categories. Further, the data met the normality, homogeneity of variance and independent of observations assumptions, which warranted the use of one-way ANOVA. All inferential statistics were done at 0.05 significant level.

\section{Results}

\subsection{Demographic Characteristics of Respondents}

Demographic information of respondents included gender, age, previous level of education, and place of residence. Table 1 presents the demographic distribution of respondents by demographic characteristics.

Table 1: Distribution of Respondents by Demographic Characteristics

\begin{tabular}{llcc}
\hline Variable & Categories & Frequency & Percentage (\%) \\
\hline Gender & Male & 212 & 53.0 \\
& Female & 188 & 47.0 \\
Age (years) & Below 20 & 22 & 5.5 \\
& $20-25$ & 334 & 83.5 \\
& $26-30$ & 39 & 9.8 \\
\multirow{5}{*}{ Previous level of Education } & Above 30 & 5 & 1.3 \\
Type of dwelling & SSS/SHS & 205 & 51.3 \\
& Tertiary & 195 & 48.7 \\
& Compound house & 237 & 59.3 \\
& Self-contained & 163 & 40.8 \\
\hline
\end{tabular}

From Table 1, there were more males than female students (53\%). The study was dominated by students within the ages 20 to 25 years (83.5\%). A little above half of the respondents were from SHS (51.3\%). Table 1 further shows that most of the respondents stayed in compound houses (59.3\%). 


\subsection{Transitional Challenges}

The study sought to find out the transitional challenges students experience in their first year in the university. Table 2 presents the challenges students face. The mean score for all the responses was 3.0. Items with mean scores from 3.0 and beyond were considered as challenges, whereas, items with mean scores below 3.0 were not considered as challenges.

Table 2: Transitional Challenges

\begin{tabular}{lcc}
\hline Challenges & $M$ & $S D$ \\
\hline Finding my way out on campus/ movement on campus & 4.2 & 1.1 \\
Compiling of timetable & 4.0 & 1.1 \\
Switching between lecture theatres & 3.6 & 1.2 \\
Making and keeping new friends & 3.6 & 1.2 \\
Coping with roommates & 3.3 & 1.3 \\
Adjusting to the new system of teaching (lecture method) & 3.3 & 1.4 \\
Separation from family and friends & 3.3 & 3.0 \\
Registration of courses & 3.0 & 1.6 \\
Coping with large class size & 2.9 & 1.4 \\
Balances personal relationships with studies & 2.8 & 1.3 \\
Finding time with other commitments such as reports, church, & 2.6 & 1.5 \\
clubbing etc. & & \\
Number of quizzes and Examination & 2.4 & 1.5 \\
Managing finances & 2.3 & 1.5 \\
Paying fees or any other study cost & 2.3 & 1.6 \\
\hline
\end{tabular}

As presented in Table 2, the major challenge of first year students during the transitional period was the difficulty in finding their way out and movement on campus $(M=4.2, S D=1.1)$. Students were also faced with some challenges: compilation of timetable $(M=4.0, S D=1.1)$, separation from family and friends $(M=3.3, S D=3.0)$, registration of courses $(M=3.0, S D=1.6)$, switching between lecture theatres $(M=3.6, S D=1.2)$, adjusting to the lecture method $(M=3.3, S D=1.4)$, making new and keeping new friends $(M=3.6, S D=1.2)$, and coping with roommates $(M=3.3, S D=1.3)$.

\subsection{Hypotheses Testing}

In order to determine the differences in the level of transitional challenges students face with regards demographic characteristics, independent samples t-test was used to determine differences with regards to gender, previous level of education, and place of residence; while one-way ANOVA was used to test for difference in terms of age. Table 3 provides a summary of the results. 
Table 3: Difference in Transitional Challenges with regards to Demographic Characteristics

\begin{tabular}{llccccc}
\hline Variables & Groups & $\mathrm{N}$ & $M$ & $S D$ & $t / F$ & $p$ \\
\hline Gender & Male & 212 & 41.8 & 7.1 & -4.744 & $.000^{*}$ \\
\multirow{3}{*}{ Previous Education level } & Female & 188 & 46.1 & 10.4 & & \\
& SSS/SHS & 205 & 46.4 & 8.8 & 5.910 & $.000^{*}$ \\
& Tertiary & 195 & 41.2 & 8.6 & & \\
Type of Dwelling & Compound & 237 & 43.0 & 8.1 & -2.172 & $.039 *$ \\
Age (years) & Self-contained & 163 & 45.0 & 10.2 & & \\
& Below 20 & 22 & 45.4 & 8.5 & .986 & .408 \\
& $20-25$ & 334 & 44.0 & 7.3 & & \\
& $26-30$ & 39 & 41.9 & 7.7 & & \\
& Above 30 & 5 & 41.2 & 8.2 & & \\
\hline
\end{tabular}

*Significant at 0.05 level (2 tailed)

The independent t-test was conducted to compare the mean scores of transitional challenges for males and females. There was a statistically significant difference in the scores for males $(M=41.8, S D=7.1)$ and females $(M=46.1, S D=10.4), t(398)=-4.74, p<.001$. The magnitude of the difference was moderate (eta squared $=.053$ ). This results implies that female students experience more transitional challenges as compared to their male counterparts.

There was also statistically significant difference in the scores of transitional challenges for students from SSS/SHS $(M=46.4, S D=8.8)$ and those from other tertiary institutions $(M=41.2, S D=8.6)$, $t(398)=5.91, p<.001$. The magnitude of the difference was medium (eta squared $=.081$ ). This results shows that students direct from SSS/SHS go through more intense transitional challenges than students who have completed other tertiary institutions like nursing training, colleges of education, polytechnics and the like.

The study further revealed a statistically significant difference in the scores of transitional for students who stay in a compound house $(M=43.0, S D=8.1)$ and those who stay in self-contained houses $(M=$ $45.0, S D=10.2), t(398)=-2.17, p=.039$. The magnitude of the difference was very small (eta squared $=$ .012). The results implies that students coming from the self-contained houses experience high transitional challenges than those from the compound houses.

A one way between-groups ANOVA was conducted to determine the differences in the transitional challenges of students with regards to their age groups. The results showed a non-significant difference in the mean scores of transitional challenges across the groups, $F(3,396)=.968, p=.408$. This implies that irrespective of the age group of students, they go through the same level of transitional challenges. The result may not be significant due the fact that the age groups were not the same in terms of numbers; some groups were overly represented.

\section{Discussion}

Among the challenges that first year university students go through, movement on campus, separation from family, registration of courses, switching between lecture theatres, adjusting to lecture method of 
teaching, making new friends, and coping with roommates are the prominent ones. It appears that these challenges are purely academics and social-related challenges. This agrees with several studies (Hazel, Catherine, \& Marvella, 2006; Jemal, 2012; Sanoff, 2006; Wangeri, Kimani, \& Mutweleli, 2012). The university campus is a new environment for freshly admitted students. This is a wider community where first year students mostly for the first time come into contact with other colleagues from diverse ethnic, cultural and economic backgrounds. Students are expected to adjust within a shorter period amidst the challenges they encounter.

It was also found that female students differ from their male counterpart in terms of transitional challenges. Females experienced more challenges as compared males. The findings agrees with Abdullah (2009). However, the findings is in contrast with Wangeri et al. (2012). Wangeri et al. found that male students were more affected in relating with each other than their female counterparts. Students from SHS experienced intense challenges than those who were from other tertiary institutions. This could be due the fact students directly from SHSs are mostly young and have not had much encounter with other people in a larger institution. However, students who are from tertiary are those who have completed teacher training colleges/colleges of education, nursing training, polytechnics, and other tertiary institutions. Most students from this category are grown-ups who have had much exposure to wider academic institutions, and for that matter they are in better position to adjust to the transition into the university.

It was further found that on the basis of place of residence, students from self-contained houses experienced higher transitional challenges compared to those staying in the compound houses. This difference is obvious in the sense that students from the compound houses stay with a couple of other tenants in the same house, whereas, students from the self-contained houses are mostly with their immediate family. Again, in Ghana, most compound houses are located at densely populated areas. Students coming from the compound houses have stayed in communities with several others, for that matter, meeting so many people in the university may not necessarily be a challenge to them. The study revealed no difference in the level of transitional challenge with regards to age. This shows that, irrespective of the age students, the level of transitional challenges is the same.

\section{Conclusion}

From the findings of the study, first year students generally are faced with academic and social-related challenges during their transition to the university. Female students experienced more challenges compared with males. It can therefore be concluded that male students adjust faster than female students during their first year on campus. Students directly from SHSs experience much challenges compare to those from tertiary institutions. This could be as a result of inexperience on the part of students from SHSs. Students from compound houses adjust more quickly in the university environment compared with those from self-contained houses. This is likely to be so because students from the compound houses are staying with a number of people, and also, in Ghana, most compound houses are found in densely populated areas. It was also concluded that first year student go throughs similar experiences irrespective their age. 


\section{Recommendations}

Based on the findings of the study, the study recommends that the orientation programmes for first year students be intensified and also place much emphasis on helping students deals with academic and social-related challenges. In addition, it is recommended that special attention be given to first year students who are females, those from densely populated areas, and those who are fresh from SHS. Special attention in this regard will help these students adjust properly during their first year and throughout their stay in the university. The findings of this study have implications for the students' affairs directors and counsellors in the university. These are individuals or officers mandated for providing academic, social, and emotional supports for students on campus. Knowledge gleaned from this research will contribute meaningfully to the development of university policies that bothers on making life comfortable on campus for students.

\section{Limitations}

Caution should be exercised in any attempt to interpret the findings of the study since first year batch for a particular year group (2016/2017) academic year was used. This may not be the case of previous batches or subsequent batches. Again, the use of self-report (questionnaire) may be a limitation to the study, there is a likelihood that respondents may provide inaccurate information.

\section{References}

Abdallah, M. C., Elias, H., Muhyddin, R., \& Uli, J. (2009). Adjustment among First Year Students in a Malaysian University. European Journal of Social Science, 8(3), 47-56.

Allen, D. F., \& Nelson, J. M. (1989). Tinto's model of college withdrawal applied to women in two institutions (Electronic version). Journal of Research and Development in Education, 22(3), 111.

Amponsah, M., \& Owolabi, H. O. (2011). Perceived stress levels of fresh university students in Ghana: A case study. British Journal of Educational Research, 1(2), 153-169.

Azila-Gbettor, E. M., Atatsi, E. A., Danku, L. S., \& Soglo, N. Y. (2015). Stress and academic achievement: Empirical evidence of business students in a Ghanaian polytechnic. International Journal of Research in Business Studies and Management, 2(4), 78-98.

Berger, J. B. (1997). Students' sense of community in residence halls, social integration, and first-year Persistence (Electronic version). Journal of College Student Development, 38, 441-452.

Berger, J. B., \& Milem, J. F. (1999). The role of student involvement and perceptions on integration in a causal model of student persistence (Electronic version). Research in Higher Education, 40(6), 641-664.

Bernier, A., Larose, S., \& Whipple, N. (2005). Leaving home for college: A potentially stressful event for adolescents with preoccupied attachment patterns. Attachment and Human Development, $7(2), 171-185$.

Birnie-Lefcovitch, S. (2000). Student perceptions of the transition from high school to university: Implications for preventative programming. (Electronic version). Journal of the First-Year Experience and Students in Transition, 12, 61-88.

Braxton, J. M., Vesper, N., \& Hossler, D. (1995). Expectations of college and student persistence (Electronic version). Research in Higher Education, 36 (5), 595-612.

Enochs, W. C., \& Roland, C. B. (2006). Social adjustment of college freshmen: the importance of gender and living environment. College Student Journal, 4(2), 32-41. 
Fisher, S., \& Hood, B. (1987). The stress of the transition to university: A longitudinal study of psychological disturbance, absent-mindedness and vulnerability to homesickness (Electronic version). British Journal of Psychology, 17(1\&2), 35-56.

Grebennikov, L., \& Skaines, I. (2009). University of Western Sydney students at risk: Profile and opportunities for change. Journal of Institutional Research, 14, 58-70.

Habibah, E., Noordin, N., \& Mahyuddin, R. H. (2010). Achievement motivation and self- efficay in relation to adjustment among university students. Journal of Social Sciences, 6(3), 333-339.

Hazel, M., Catherine, E., \& Marvella, A. (2006). Perceived racial discrimination, social support, and psychological adjustment among African American College Students. Journal of Black Psychology 32(4) 442-454.

Jemal, J. (2012). Assessing major adjustment problems of freshman students in Jimma University. Ethiopian Journal of Education \& Science, 7(2), 1-14.

Keup, J. R., \& Stozenberg, E. B. (2004). The 2003 Your First College Year (YFCY) Survey: Exploring the academic and personal experiences of first- year students (Monograph No. 40), Columbia, SC: University of South Carolina, National Resource Centre for the First-Year Experience and Students in Transition. Retrieved March 2017, from http://www.freepatentsononlin.com

Krejcie, R. V., \& Morgan, D. W. (1970). Determining sampling size for research activities. Educational and Psychological Measurement, 30, 607-610.

McInnis, C. (2001). Researching the first year experience: Where in from here? Higher Education Research and Development 20(2), 105-114.

Mudhovozi, F. (2012). Social and academic adjustment of first-year university students. Journal of Social Science, 33(2), 251-259.

Owusu, G. A., Tawiah, M. A., Sena-Kpeglo, C., \& Onyame, J. T. (2014). Orientation impact on performance of undergraduate students in University of Cape Coast (Ghana). International Journal of Educational Administration and Policy Studies, 6(7), 131-140.

Perry, C., \& Allard, A. (2003). Making the connections: Transition experiences for first-year education students. Journal of Educational Enquiry, 4 (2), 74-89.

Sanoff, A. P. (2006). A perception gap over students' preparation. Chronicle of Higher Education, 52(27), 9-14.

Students Records Management and Information System of UCC (SRMIS, 2017). Students' population. Cape Coast: Author.

Tao, S., Dong, Q., Pratt, M., Hunsberger W, \& Pancer, S. (2000). Social support: Relations to coping and adjustment during the transition to university in the People's Republic of China. Journal of Adolescent Research, 15, 123-144.

Upcraft, M. L., \& Famsworth, W. E. (1984). Orientation programs and activities. In M. L. Upcraft (Ed.), New directors for student services: Orienting students to college (pp. 27-37). San Francisco: Jossey-Bass.

Wangeri, T., Kimani, E., \& Mutweleli, S. M. (2012). Transitional challenges facing university first year students in Kenyan public universities: A case of Kenyatta University. Interdisciplinary Review of Economics and Management 2(1), 41-50. 